\title{
Doğu Karadeniz Bölgesindeki Bazı Doğal Kaynak Sularının Elemental Analizi ve Haritalandırıması ile Çevre ve İnsan Sağlığına Etkilerinin Araştırılması
}

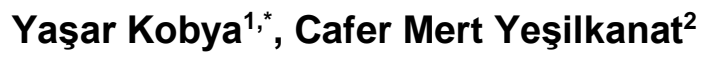 \\ ${ }^{1}$ Artvin Çoruh Üniversitesi, Mühendislik Fakültesi, Enerji Sistemleri Mühendisliği Bölümü, 08100, Artvin. \\ ${ }^{2}$ Artvin Çoruh Üniversitesi, Eğitim Fakültesi, Matematik ve Fen Bilimleri Eğitimi Bölümü, 08000, Artvin.
}

\section{Özet}

Bu çalışmada, Doğu Karadeniz Bölgesi’ndeki 7 ildeki (Artvin, Rize, Trabzon, Giresun, Ordu, Gümüşhane ve Bayburt) doğal kaynak sularının elemental analizinin yapılması ve bu analiz yardımıyla, jeoistatistik analiz kullanılarak bölgenin tamamının elemental olarak dağllımının belirlenmesi amaçlanmıştır. Bu amaç doğrultusunda, Doğu Karadeniz Bölgesi'ndeki 40 adet doğal kaynak suyu örneğinde ICP-OES cihazı yardımı ile elemental analiz (Na, $\mathrm{Al}, \mathrm{P}, \mathrm{Cl}, \mathrm{K}, \mathrm{Ca}, \mathrm{V}, \mathrm{Mn}, \mathrm{Fe}, \mathrm{Ni}, \mathrm{Cu}, \mathrm{Zn}$ ) yapılmıştır. Her bir element için Doğu Karadeniz Bölgesi'ndeki ortalama kimyasal analiz değerleri sirastyla; 10270, 215, 122, 4749, 1093, 15960, 59, 5, 89, 18,10 ve 90 $\mu \mathrm{g} / \mathrm{L}$ olarak bulunmuştur. Elde edilen sonuçların genel olarak Dünya Sağllk Örgütü ve Türkiye Cumhuriyeti Să̆lık Bakanlı̆̆l 'nın izin verilebilir değerleri ile uyumlu olduğu görülmüşürr. Ayrıca dünya üzerinde farklı noktalarda gerçekleştirilen benzer çalışmalarla da yapılan karşılaştırma neticesinde genel bir uyum gözlenmiştir. Jeoistatistik analiz kullanılarak her bir elementin çalışma alanındaki dağılımı belirlenmiş ve haritalandırılmıştır. Bu dağılım haritaları vasıtasıyla, numune alınmamıs yerlerdeki suların da kimyasal dağllımları hakkında tahmini bir sonuç elde edilebilmiştir. Son olarak, bu çalışmada analiz edilen elementlerin insan sağllğ için olası etkileri ve hangi bölgelerin element fazlalığı dolayısıyla risk altında olduğu tartışılmıştır.

$\underline{\text { Anahtar Sözcükler }}$

Doğal Kaynak Suları, Elemental Analiz, Jeoistatistiksel Analiz, Sağlık Riski, Doğu Karadeniz Bölgesi

\section{Elemental Analysis and Mapping of Some Natural Waters in Eastern Black Sea Region and Investigation of Their Effects on Environment and Human Health}

\begin{abstract}
In this study, it was aimed to make an elemental analysis of the natural spring waters in 7 cities (Artvin, Rize, Trabzon, Giresun, Ordu, Gümüşhane and Bayburt) in the Eastern Black Sea region and to determine the elemental distribution of the entire region using geostatistical analysis with the help of this analysis. In accordance with this purpose, elemental analyses ( $\mathrm{Na}, \mathrm{Al}, \mathrm{P}, \mathrm{Cl}, \mathrm{K}, \mathrm{Ca}, \mathrm{V}, \mathrm{Mn}$, $\mathrm{Fe}, \mathrm{Ni}, \mathrm{Cu}, \mathrm{Zn}$ ) were carried out with the help of ICP-OES device for 40 samples of natural spring water in Eastern Black Sea Region. The average chemical analysis values for each element in Eastern Black Sea Region were as 10270, 215, 122, 4749, 1093, 15960, 59, 5, 89, 18, 10 and $90 \mu \mathrm{g} / \mathrm{L}$, respectively. The results were generally consistent with the permissible limits of World Health Organization and the Ministry of Health of the Republic of Turkish. In addition, a general harmony was observed as a result of the comparison made with similar studies carried out at different points in the world. Using geostatistical analysis, the distribution of each element was determined and mapped in the study area. By means of these distribution maps, an estimated result could also be obtained about the chemical distributions of waters in unsampled locations. Finally, the possible effects of the analyzed elements on human health and which areas being under risk due to excess elements were discussed in this study.
\end{abstract}

\section{$\underline{\text { Keywords }}$}

Natural Spring Water, Elemental Analysis, Geostatistical Analysis, Health Risk, Eastern Black Sea Region

\section{Giriş}

Çok küçük mikroskobik canlı organizmadan en büyük canlı varlığa kadar bütün biyolojik yaşamı besleyen su, canlı yaşamının devamlılığı için gerekli olan en önemli elemanlardan biridir. İnsan hayatı için son derece gerekli ve zorunlu olan su, insan sağlığı üzerinde herhangi bir zararlı etkiye sebep vermemek için de mümkün olduğunca temiz olmalıdır. Suyun temiz olması ifadesinin anlamı, yapısında insan sağlığı açısından tehlike oluşturabilecek maddelerin bulunmamasıdır. Fakat suyun doğal ortamda tamamen saf bir şekilde korunması mümkün değildir. Çünkü yapı yönünden kararlı bir bileşik olan su, diğer maddelerle temas ettiğinde olağanüstü çözücü özelliğe sahiptir. 
$\mathrm{Su}$, toprak katmanlarından süzülerek geçerken, temas ettiği maddeleri de yapısına çeker. Suya karışan maddelerin bir bölümü doğal toprak bileşenlerinden, bir kısmı da sanayi, ev ve tarımsal atıklardan ileri gelmektedir. Suya karışan maddelerin diğer bir bölümünü ise mineraller oluşturur. Bu minerallerin bir kısmı vücut için gerekli olmakla birlikte, bir kısmı da sağlık açısından risk unsuru taşımaktadır.

İnsanların tükettiği doğal kaynak sularında bulunabilecek her türlü yabancı madde belirli bir konsantrasyonun üzerinde insan sağlığı için tehdit oluşturabilmektedir. İnsan sağlığını tehdit eden bu maddelerden bazıları toksin maddeler olarak adlandırılır ki, bu maddelerin sularla çok düşük (eser) miktarlarda bile bulunmaları birçok tehlikeli hastalığa hatta ölüme dahi neden olabilmektedir. Çok az miktarları bile insan sağlığına zararlı olabilecek özellikte olabilen bu maddelerin en önemlileri, ağır metaller ya da element olarak adlandırılan $\mathrm{Cu}, \mathrm{Cd}, \mathrm{Cr}, \mathrm{Be}, \mathrm{Ag}, \mathrm{As}, \mathrm{Mn}, \mathrm{Hg}, \mathrm{Ni}, \mathrm{Pb}, \mathrm{Sb}, \mathrm{Se}, \mathrm{Te}, \mathrm{Zn}, \mathrm{U}$ ve $V$ gibi elementlerdir.

Son yıllarda sularda ağır metal kirliliğinin insan sağlı̆̆ için oluşturduğu tehditler daha iyi anlaşılmaya başlandığından, içme sularında eser element miktarlarının belirlenmesi için yapılan çalışmalar hız kazanmıştır. Literatürde bu konu üzerine yapılmış birçok çalışmaya rastlamak mümkündür (Fatima vd. 2007; Karamanis vd. 2007; Dabeka vd. 2002; Rusconi vd. 2004; Rosborg vd. 2005; Alabdula'aly ve Khan 2009; Ahmad vd. 2010; Virha vd. 2011).

Bu çalışmanın amacı; Doğu Karadeniz Bölgesinde bulunan 7 ildeki (Artvin, Rize, Trabzon, Giresun, Ordu, Gümüşhane ve Bayburt) doğal kaynak suyu numunelerinde elemental analiz işlemi yapılarak, sularda bulunan ağır metal miktarlarını belirlemek ve bunların insan sağlığı üzerine oluşturabileceği olası zararlı etkileri araştırmaktır. Ayrıca elde edilen bu elemental analiz sonuçları yardımı ile çalışma bölgesinde her bir element için tahmini dağılım haritalarının da üretilmesi amaçlanmıştır.

\section{Materyal ve Metot}

\section{1. Çalışma Alanı ve Analiz İşlemi}

Çalışma alanında belirlenen 40 adet istasyondan (Şekil 1) toplanarak 2'şer litrelik kaplara koyulan su numunelerin her biri, içerisinde herhangi bir tortu oluşumunu engellemek için adi süzgeç kâğıdı ile süzülerek 10mL'lik marinelli yani steril kaplara alınmış ve sayıma hazır hale getirilmiştir.
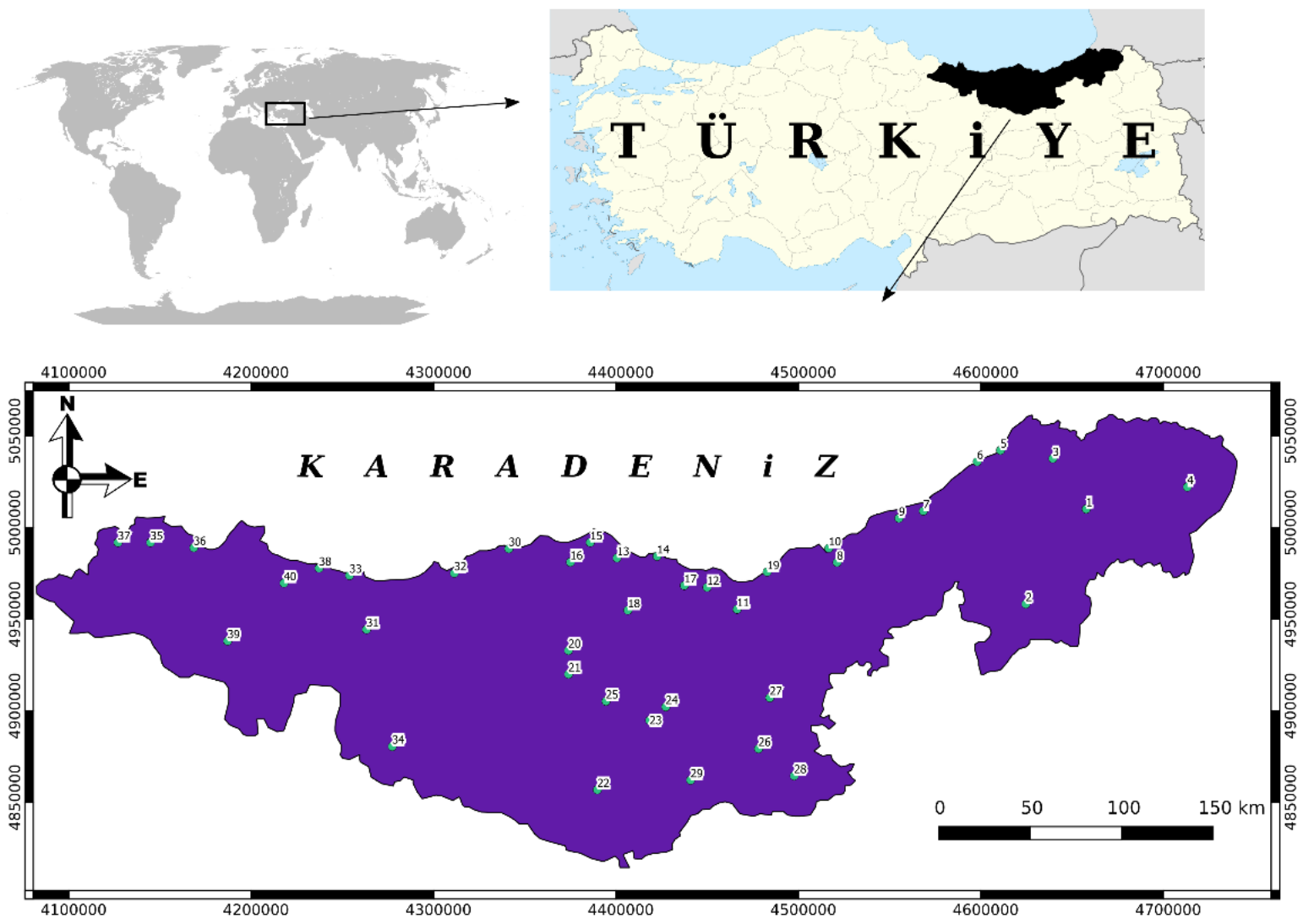

Şekil 1: Çalışma alanı ve ölçüm alınan istasyonlar 
Sayıma hazır hale getirilen su numuneleri ICP-OES cihazı ile analiz edilmiştir. ICP-OES kimyasal analiz cihazı, eş zamanlı ölçümler sağlayan, otomatik bir optik yayma spektrometresidir. Bu cihazda, indüklenerek çiftlenmiş plazma uyarılmasını ve sıvıların nicelik ile yarı nicelik analizi için detektör sistemine dayalı bir yarı iletken kullanır. Sıvı örneği buharlaştırılır ve plazma içine bir aerosol olarak beslenir. Plazmanın yüksek sıcaklığı (6000K-8000K) numuneyi buharlaştırır ve numunenin içerisinde var olan moleküller, atomlarına ayrılarak uyarılırlar ve kısmen iyonize edilirler. Uyarılmış atom ve iyonlar elemente özgü bir radyasyon yayarlar. Bir iletim optiği, optik sistemin içindeki bu radyasyonu besler. Yayılan radyasyon, optik sistemde bileşenlerine kırınır. Şiddet, yarı iletken detektörler kullanılarak ölçülür. Birim sinyal ölçme sürecinden sonra, ölçülen element şiddetleri Smart Analyzer yazılımı ile değerlendirilir. Yöntemler ölçümden önce ayarlanır. Her element için belirlenen kalibrasyon fonksiyonları bu yöntemlerde saklıdır. Konsantrasyonlar bu yöntemler kullanılarak, ölçülen şiddetlerden hesaplanır. Böylece istenilen her bir elementin konsantrasyonu bulunmuş olur (Kobya 2009).

\subsection{Haritalandırma ve Program Kaynakları}

Dağılım haritaları jeoistatistik yöntem ile oluşturulmuştur. Bu yöntemde, numuneler arasındaki iliş̧i aralarındaki öklidyen mesafe ile değerlendirilir (Armstrong 1998). Klasik istatistikte sadece ölçüm sonuçları değerlendirilirken jeoistatistik metotlarda numuneler arası uzaklık değerleri de hesaba katılır (Webster ve Oliver 2007). Numuneler arasındaki mesafe ile değişkenlik miktarı variogram fonksiyonları ile hesaplanır (Sarma 2009). Variogram fonksiyonu mekansal değişkenlerin aralarındaki uzaklıkla ilişkilerini ortaya çıkarır. Ayrıca çalışmada kullanılan ve önemli bir jeoistatistik yöntem olan Kriging (Krige 1966) için ağırlıkların belirlenmesinde önemlidir (Isaaks ve Srivastava 1989). Literatürde en iyi lineer yansız tahmin edici olarak geçen Kriging yöntemi, istatistikteki ağırlıklı ortalama teoremine oldukça benzerdir (Baume vd. 2011). Kriging yöntemi son yıllarda birçok farklı mekansal değişkenin dağılımının belirlenmesinde oldukça sık kullanılan bir yöntem olarak öne çıkmaktadır. Maden yapılarının değerlendirilmesinde (Tavares vd. 2008), yer altı ve yer üstü sularının kalite parametrelerinin dağllımlarının incelenmesinde (Dragović vd. 2012), toprak yapısının araştırması ve haritalanmasında (Pérez-Rodríguez vd. 2007), Radyolojik dağılımların belirlenmesinde ve ağır metal kirliliğinin konumsal değerlendirmesinde (McGrath vd. 2004; Xie vd. 2011)

$\mathrm{Bu}$ çalışmada oluşturulan haritalar $100 \times 100 \mathrm{~m}^{2}$ 'lik mekansal çözünürlük derecesinde oluşturulmuştur. Haritaların oluşturulmasında $R$ programlama dili (Ihaka ve Gentleman 1996; R Development Core Team 2005) ve Gstat (Pebesma ve Wesseling 1998) ve $s p$ (Pebesma ve Bivand 2005) $R$ kütüphane dosyaları kullanılmışır. Haritaların düzenlenmesinde ise QGIS (Quantum GIS Development Team 2014) açık kaynak kodlu programından yararlanılmıştır.

\section{Bulgular}

\subsection{Elemental Analiz Sonuçları}

ICP-OES cihazı ile doğal kaynak sularında yapılan kimyasal analiz sonucunda elde edilen veriler Tablo 1'de görülmektedir. Tablo 1'deki değerler göz önüne alındığında aşă̆ıldaki değerlendirmeler yapıllabilir.

Tablo 1'e genel bir bakışla; en düşük değerlerin $N a$ için Artvin Borçka, $A l$ için Gümüşhane Kürtün ve Giresun Sebinkarahisar'da, $P$ için Gümüşhane Kürtün'de, $C l$ için Trabzon Vakfikebir'de, $K$ için Artvin Merkezde, $C a$ için Ordu Ünye'de, $V$ için Trabzon Köprübaşı ve Ordu İkizce'de, $M n$ için Artvin Yusufeli, Trabzon Arsin ve Çarşıbaşı ve Gümüşhane Kürtün'de, $\mathrm{Fe}$ için Ordu Merkezde, $\mathrm{Ni}$ için Artvin Yusufeli ve Trabzon Arsin'de, $\mathrm{Cu}$ için Artvin Arhavi ve Gümüşhane Kürtün'de, $Z n$ için Artvin Borçka ve Trabzon Köprübaşı'nda olduğu görülmektedir.

En yüksek değerlerin ise $\mathrm{Na}$ için Ordu Merkezde, $\mathrm{Al}$ için Trabzon Akçaabat'ta, $P$ için Giresun Merkez'de, $\mathrm{Cl}$ için Ordu Fatsa'da, $K$ için Artvin Murgul'da, $C a$ için Gümüşhane Kale'de, Trabzon Çarşıbaşı'nda, $M n$ için Artvin Arhavi'de, $\mathrm{Fe}$ için Trabzon Akçaabat'ta, $\mathrm{Ni}$ için Trabzon Köprübaşı'nda, $\mathrm{Cu}$ için Artvin Murgul'da, $\mathrm{Zn}$ için Trabzon Beşikdüzü’nde olduğu bulunmuştur. Elementlerin en yüksek değerleri beklenildiği gibi daha çok maden bölgeleri olan Artvin, Gümüşhane ve Trabzon'dadır.

Tablo 2'de bu çalışmanın verileriyle WHO'nun verileri karşılaştırıldığında, bu çalışma verilerinin tamamıyla WHO'nun sınır değerlerinin altında olduğu görülmektedir. Sağlık Bakanlığı'nın 2005 yılında yaptığı çalışma ile kıyaslama yapıldığında ise doğal kaynak sularında $A l$ ve $F e$ 'in ortalama değerlerinin Sağlık Bakanlığı'nın sinır değerlerinin üzerine çıktığı görülmüştür. Diğer elementler ise sınır değerlerinin altındadır. Ayrıca bu çalışma sonuçları ile dünya üzerindeki benzer çalışmaların sonuçları da birbirleri ile örtüşmektedir.

\subsection{Jeoistatistik Analiz ve Haritalandırma}

Çalışmada belirlenen elementlere ait dağılım haritalarının oluşturulması için öncelikle her bir elemente ait histogram dağılımlarının tespiti yapılmıştır. Jeoistatistiksel analiz hesaplamaları için verilerin normal (gaussian) dağılıma uyması beklenir. Çünkü jeoistatistik analizde dağılımın normal olmaması variogramın yapısını bozarak tahmin ağırlıklarının yanlış hesaplanmasına yol açabilir. Bu yüzden sık sık log-normal olan deneysel veriler, normal dağılıma uymasını sağlamak için veri dönüşümleri uygulanır (McGrath vd. 2004). 
Şekil 2'de her bir element değeri için histogram eğrileri gösterilmiştir. Bu eğrilerden tüm elementlerin log-normal bir dağılım sergilediği belirlenebilir. Dağılımın uygun şekilde belirlenebilmesi için tüm verilere logaritmaları alınarak normal dağılıma yaklaştırtılması sağlanmıştır.

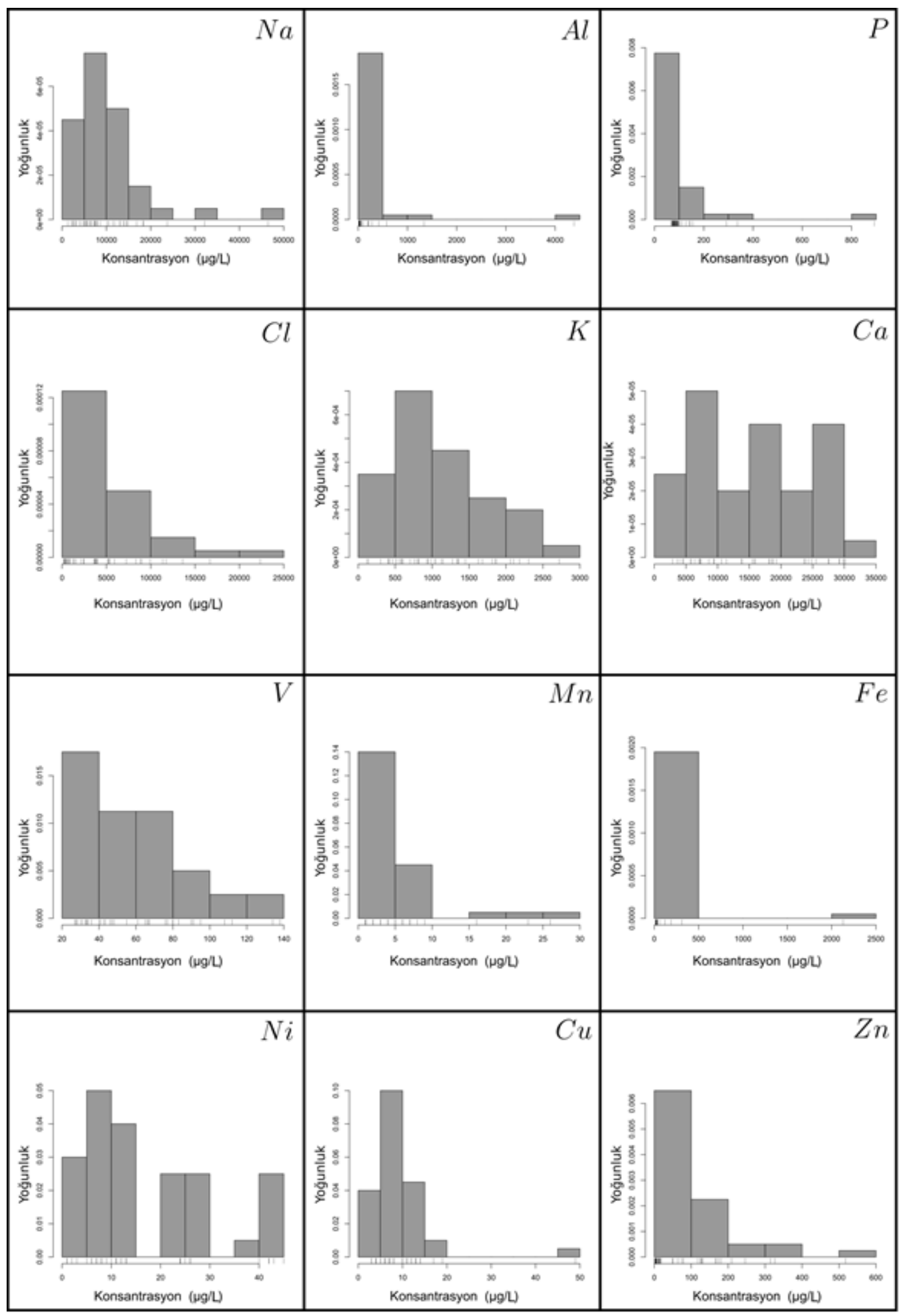

Şekil 2: Çalışma alanında belirlenen elementler için histogram dağılımları 
Veri dönüşümünden sonra her bir element için variogram değişimleri belirlenir ve ölçüm alınmamış ara değer noktaları için tahmin değerleri hesaplanabilir. Tahmin sonuçları her bir mekansal piksel üzerinde uygun renklerle sembolize edildiğinde dağılım haritaları oluşturulur. Şekil 3'te her bir element için oluşturulan dağılım haritaları gösterilmektedir. Haritalar genel olarak değerlendirildiğinde, $A l, P$ ve $F e$ konsantrasyon dağılımının tüm çalışma alanında düşük düzeyde olduğu; $\mathrm{Na}, \mathrm{Cl}, \mathrm{V}, \mathrm{Mn}, \mathrm{Ni}, \mathrm{Cu}$ ve $\mathrm{Zn}$ konsantrasyon dağılımının ise tüm çalışma alanında ortalama bir şekilde homojen olarak dağıldığı görülmüştür. $K$ ve $C a$ konsantrasyon dağılımları ise özellikle çalışma alanının genel ortalamasından fazla olduğu tespit edilmiştir.

Tablo 1: Illere göre kimyasal analiz değerleri $(\mu g / L)$

\begin{tabular}{|c|c|c|c|c|c|c|c|c|c|c|c|c|c|}
\hline \multicolumn{2}{|c|}{ Numuneler } & $\mathbf{N a}$ & Al & $\mathbf{P}$ & Cl & $\mathbf{K}$ & $\mathrm{Ca}$ & V & Mn & $\mathbf{F e}$ & $\mathbf{N i}$ & $\mathbf{C u}$ & $\mathbf{Z n}$ \\
\hline \multirow{6}{*}{$\sum_{2}^{3}$} & Merkez & 13851 & 24 & 76 & 2166 & 119 & 27478 & 108 & 6 & 20 & 11 & 8 & 326 \\
\hline & Yusufeli & 7964 & 19 & 83 & 391 & 609 & 24792 & 67 & 1 & 18 & $<\mathrm{DL}$ & 6 & 132 \\
\hline & Borçka & 1315 & 1337 & 74 & 3618 & 137 & 4604 & 28 & 3 & 311 & 42 & 4 & $<\mathrm{DL}$ \\
\hline & Şavşat & 14104 & 34 & 104 & 11715 & 2718 & 15484 & 43 & 6 & 22 & 24 & 49 & 6 \\
\hline & Hopa & 7229 & 18 & 127 & 888 & 812 & 15964 & 36 & 7 & 20 & 9 & 10 & 19 \\
\hline & Arhavi & 5639 & 16 & 86 & 3892 & 589 & 3971 & 33 & 26 & 18 & 42 & 3 & 14 \\
\hline \multirow{4}{*}{$\stackrel{\mathscr{N}}{\mathbb{*}}$} & Ardeşen & 11895 & 27 & 78 & 8911 & 1126 & 18654 & 66 & 2 & 23 & 8 & 7 & 125 \\
\hline & Güneysu & 5573 & 26 & 89 & 1367 & 516 & 5870 & 33 & 5 & 24 & 43 & 6 & 12 \\
\hline & Pazar & 5092 & 20 & 94 & 905 & 1039 & 13804 & 43 & 4 & 18 & 1 & 4 & 51 \\
\hline & Merkez & 5162 & 20 & 73 & 3692 & 978 & 7202 & 43 & 6 & 22 & 10 & 8 & 75 \\
\hline \multirow{9}{*}{ 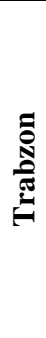 } & K.Baş1 & 4390 & 57 & 93 & 1562 & 820 & 3567 & 27 & 4 & 38 & 45 & 12 & $\angle \mathrm{DL}$ \\
\hline & Arsin & 10546 & 19 & 89 & 11360 & 941 & 15745 & 95 & 1 & 19 & $<\mathrm{DL}$ & 10 & 246 \\
\hline & Akçaabat & 3930 & 4383 & 156 & 1243 & 788 & 7036 & 55 & 23 & 2129 & 13 & 13 & 8 \\
\hline & Beşikdüzü & 7847 & 27 & 143 & 7242 & 2304 & 8607 & 48 & 8 & 22 & 26 & 12 & 518 \\
\hline & Çarşıbaş1 & 10146 & 210 & 292 & 5350 & 1451 & 18161 & 138 & 1 & 189 & 6 & 5 & 2 \\
\hline & V.Kebir & 2097 & 100 & 85 & 156 & 403 & 7286 & 33 & 2 & 19 & 2 & 5 & 13 \\
\hline & Yomra & 7181 & 42 & 82 & 3657 & 1679 & 6395 & 83 & 5 & 27 & 3 & 13 & 180 \\
\hline & Maçka & 14732 & 26 & 70 & 13597 & 1278 & 24287 & 77 & 3 & 21 & 8 & 7 & 168 \\
\hline & Of & 7389 & 22 & 112 & 4012 & 469 & 10614 & 41 & 3 & 24 & 24 & 8 & 1 \\
\hline \multirow{6}{*}{ 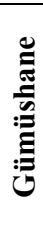 } & Kürtün & 6063 & 15 & 69 & 5340 & 1148 & 19262 & 67 & 1 & 18 & 6 & 3 & 128 \\
\hline & Torul & 16821 & 580 & 71 & 476 & 1346 & 29822 & 112 & 16 & 20 & 26 & 8 & 314 \\
\hline & Kelkit & 18210 & 40 & 82 & 8343 & 2059 & 29213 & 90 & 5 & 26 & 12 & 17 & 209 \\
\hline & Kale & 14651 & 31 & 96 & 16685 & 1624 & 30187 & 80 & 4 & 22 & 13 & 14 & 15 \\
\hline & Y.Dere & 6389 & 195 & 70 & 8911 & 516 & 13829 & 40 & 3 & 23 & 25 & 7 & 4 \\
\hline & Merkez & 7539 & 20 & 82 & 575 & 703 & 23666 & 65 & 7 & 19 & 26 & 7 & 127 \\
\hline \multirow{4}{*}{$\stackrel{\bar{\partial}}{\bar{D}}$} & Süly. Çeş. & 3163 & 22 & 80 & 419 & 583 & 29214 & 34 & 7 & 19 & 26 & 8 & 5 \\
\hline & Narkazan & 6591 & 26 & 83 & 3870 & 1040 & 27592 & 46 & 7 & 21 & 11 & 13 & 6 \\
\hline & Maden & 2428 & 20 & 75 & 277 & 758 & 25516 & 76 & 3 & 20 & 26 & 7 & 165 \\
\hline & Demirözü & 11393 & 29 & 77 & 781 & 304 & 23852 & 47 & 1 & 21 & 24 & 5 & 64 \\
\hline \multirow{5}{*}{ 氕 } & Görele & 18404 & 281 & 337 & 2432 & 1346 & 11401 & 91 & 3 & 22 & 8 & 11 & 118 \\
\hline & Merkez & 2588 & 40 & 892 & 249 & 409 & 7334 & 31 & 1 & 22 & 24 & 6 & 5 \\
\hline & Espiye & 13046 & 42 & 89 & 5148 & 2105 & 9404 & 40 & 3 & 26 & 11 & 14 & 4 \\
\hline & Bulancak & 13040 & 23 & 144 & 5219 & 1851 & 29238 & 61 & 9 & 21 & 8 & 10 & 3 \\
\hline & Ş.Karahisar & 32120 & 15 & 75 & 9940 & 559 & 29941 & 80 & 3 & 19 & 12 & 8 & 174 \\
\hline \multirow{6}{*}{ 롤 } & Ünye & 8577 & 77 & 91 & 3834 & 1869 & 2869 & 30 & 3 & 34 & 42 & 11 & 13 \\
\hline & Fatsa & 23723 & 18 & 83 & 22365 & 2181 & 4447 & 28 & 4 & 20 & 5 & 8 & 7 \\
\hline & İkizce & 4947 & 417 & 99 & 2485 & 934 & 5686 & 27 & 4 & 120 & 13 & 19 & 10 \\
\hline & Gülyalı & 5574 & 17 & 91 & 5926 & 1352 & 18719 & 43 & 1 & 19 & 40 & 4 & 49 \\
\hline & Gölköy & 2971 & 206 & 98 & 261 & 430 & 9474 & 34 & 2 & 59 & 7 & 6 & 16 \\
\hline & Merkez & 46471 & 42 & 81 & 685 & 1810 & 18222 & 134 & 1 & 15 & 7 & 10 & 79 \\
\hline \multicolumn{2}{|c|}{ Minimum } & 1315 & 15 & 69 & 156 & 119 & 2869 & 27 & 1 & 15 & $<\mathrm{DL}$ & 3 & $<\mathrm{DL}$ \\
\hline \multicolumn{2}{|c|}{ Maksimum } & 46471 & 4383 & 892 & 22365 & 2718 & 30187 & 138 & 26 & 2129 & 45 & 49 & 518 \\
\hline \multicolumn{2}{|r|}{ Ortalama } & 10270 & 215 & 122 & 4749 & 1093 & 15960 & 59 & 5 & 89 & 18 & 10 & 90 \\
\hline
\end{tabular}


Tablo 2: Sonuçların diğer çalışmalarla karşılaştırılması $(\mu \mathrm{g} / \mathrm{L})$

\begin{tabular}{|c|c|c|c|c|c|c|c|c|}
\hline & Türkiye $^{1}$ & Pak. $^{2}$ & Yun. $^{3}$ & İsv. $^{4}$ & Kan. $^{5}$ & WHO $^{6}$ & S.B. ${ }^{7}$ & Ç.O.B. ${ }^{8}$ \\
\hline 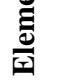 & $\begin{array}{c}\text { Doğal } \\
\text { kaynak suyu }\end{array}$ & $\begin{array}{l}\text { İçme } \\
\text { suyu }\end{array}$ & $\begin{array}{l}\text { İçme } \\
\text { suyu }\end{array}$ & $\begin{array}{l}\text { İçme } \\
\text { suyu }\end{array}$ & $\begin{array}{l}\text { İंçme } \\
\text { suyu }\end{array}$ & $\begin{array}{l}\text { İçme } \\
\text { suyu }\end{array}$ & $\begin{array}{c}\text { Doğal } \\
\text { kaynak suyu }\end{array}$ & $\begin{array}{c}\text { Doğal } \\
\text { kaynak suyu }\end{array}$ \\
\hline $\mathbf{N a}$ & 10270 & 23618 & _ & - & _ & _ & 30000 & 125000 \\
\hline Al & 215 & - & - & - & - & - & 50 & 300 \\
\hline $\mathbf{P}$ & 122 & - & - & - & - & - & - & - \\
\hline Cl & 4749 & 25882 & - & - & - & - & 40000 & - \\
\hline $\mathbf{K}$ & 1093 & 1745 & - & - & - & - & 10000 & - \\
\hline $\mathbf{C a}$ & 15960 & 27100 & - & - & - & - & 100000 & - \\
\hline $\mathbf{V}$ & 59 & - & 0.72 & 0.39 & 0.32 & 70 & - & - \\
\hline Mn & 5 & - & 1.24 & 1 & 0.57 & 500 & 20 & 100 \\
\hline $\mathrm{Fe}$ & 89 & - & 1.25 & 2 & - & - & 50 & 300 \\
\hline $\mathbf{N i}$ & 18 & - & 0.56 & 0.42 & 0.73 & 20 & 20 & 20 \\
\hline $\mathrm{Cu}$ & 10 & - & 0.43 & 1.53 & 0.9 & 2000 & 100 & 20 \\
\hline Zn & 90 & - & 1.1 & 3.38 & 1.6 & - & 5000 & 200 \\
\hline
\end{tabular}

\section{Sonuçlar}

Bu çalışmada, Doğu Karadeniz Bölgesi'ndeki doğal kaynak sularının ağır metal kirlilik dağılımı belirlenmiştir. Ayrıca jeoistatistik yöntemler ile ölçüm alınamayan noktalarda her bir element için dağılımın nasıl değiştiği tahmin edilmiştir. $\mathrm{Bu}$ tahmin değerleri ile her bir element için dağılım haritaları oluşturulmuştur. Yapılan ölçümler sonucunda Doğu Karadeniz Bölgesi’ndeki doğal kaynak sularında genel anlamda ve kısa vadede insan sağlı̆̆ını tehdit edebilecek seviyede bir element bulunmamıştır. Buna ek olarak, bu çalışmada elde edilen sonuçların genel anlamda gerek Dünya Sağlık Örgütü gerekse Sağlık Bakanlığı'nın belirlediği sınır değerlerin altında olduğu görülmüştür. Ancak insanların içtikleri sularla vücutlarına aldıkları bu elementler zamanla vücudun belirli organlarında birikmekte ve sağlık için tehlikeli miktarlara ulaşabilmektedir. Örneğin vücutta $N a$ fazlalığı $K$ kaybı ile yüksek tansiyona, vücutta su birikmesi ile ödem oluşmasına ve ileri süreçte kalıcı böbrek rahatsızlıklarına neden olabilmektedir.

$\mathrm{Bu}$ bağlamda, Şekil 3'deki $\mathrm{Na}$ dağılım haritası incelendiğinde Gümüşhane ve Ordu-Giresun arasında yaşayan insanların nispeten risk altında olduğu söylenebilir. $A l$ fazlalığ insanda sinir sistemine zarar verebilmektedir ve Artvin, Trabzon ve Gümüşhane'de bu riskin daha fazla olduğu $A l$ dağılım haritasından anlaşılmaktadır. $P$ fazlalığ vücutta $C a$ dengesini bozarak kemiklerin gücünü azaltabilmekte ve yüksek tansiyona sebep olabilmektedir. Yine $P$ dağılım haritasından böyle bir riskin Ordu-Giresun arasında yaşayan insanlar için biraz daha fazla olduğu söylenebilir. Vücutta $\mathrm{Cl}$ fazlalığı ise hücre yapısına zarar verebilmekte dolayısıyla kansere dönüşebilmektedir. $\mathrm{Cl}$ için dağılım haritasına bakıldığında Doğu Karadeniz Bölgesi'nin genelinde yüksek değerlere rastlamakta ve bu bölgede yaşayan insanların kanser riski taşıdıkları düşünülmektedir. $K$ fazlalığı ise kusma, yorgunluk, kalp ve beyin rahatsızlıkları hatta ani kalp durmalarına neden olabilmektedir. Yine $K$ dağılım haritası incelendiğinde tüm Doğu Karadeniz Bölgesi insanlarının $K$ fazlalığından kaynaklanan sağlık risklerini taşıyabileceği anlaşılmaktadır.

İnsan vücudunda $C a$ fazlalığında böbrek taşı ve kireçlenmesi, kas güçsüzlüğü gibi sorunlar yaşanabilir. $C a$ fazlalığı Gümüşhane, Bayburt ve Artvin'in üst kısımlarında biraz daha fazladır ve buralarda yaşayan insanlar için risk oluşturmaktadır. $V$ fazlalığında solunum sıkıntıları, nörolojik sıkıntılar ve bazı kanser türleri oluşabilir. Yine $V$ dağılım haritasına bakıldığında çalışma alanının hemen tamamında riskin fazla olduğu görülmektedir. $M n$ fazlalığı solunum sıkıntıları, nörolojik sıkıntılar, parkinson benzeri nörolojik bozukluklar ve kansere neden olabilir. Mn dağılım haritasından Artvin, Trabzon, Giresun sahil kesimi ile Gümüşhane'de yaşayan insanların nispeten biraz daha fazla $M n$ fazlalı̆̆ı riski taşıdığı varsayılmaktadır. Karaciğerde siroz, pankreasta fibrosis, şeker ve kalp rahatsızlıkları vücutta $F e$ fazlalığı ile ortaya çıkabilmektedir. Bu bakımdan Trabzon ve Artvin'in risk altında olduğu $F e$ dağılım haritasından görülmektedir. Vücutta $N i$ fazlalığında ise, solunum sorunları, dermotid ve akciğer kanseri gibi rahatsızlıklarla karşılaşılabilir. Ni fazlalığı ve bunun neden olduğu riskler hemen hemen Doğu Karadeniz Bölgesi’nin tamamında mevcuttur. $C u$ fazlalığı karaciğer ve beyin hasarlarına bunlardan kaynaklanan çeşitli hastalıklara neden olabilmektedir. 
$C u$ fazlalığı riski en fazla Artvin ilinde gözlenmektedir. Son olarak $Z n$ fazlalığı vücutta $F e$ ve $C u$ 'yu azaltarak bağışıklık sistemini zayıflatır ve buna bağlı olarak halsizlik, kusma, öksürük, sarılık gibi rahatsızlıkları tetikler. Doğu Karadeniz Bölgesi'nde Zn fazlalığı riskinin Artvin, Rize, Trabzon, Gümüşhane ve Bayburt'ta daha fazla olduğu anlaşılmaktadır.

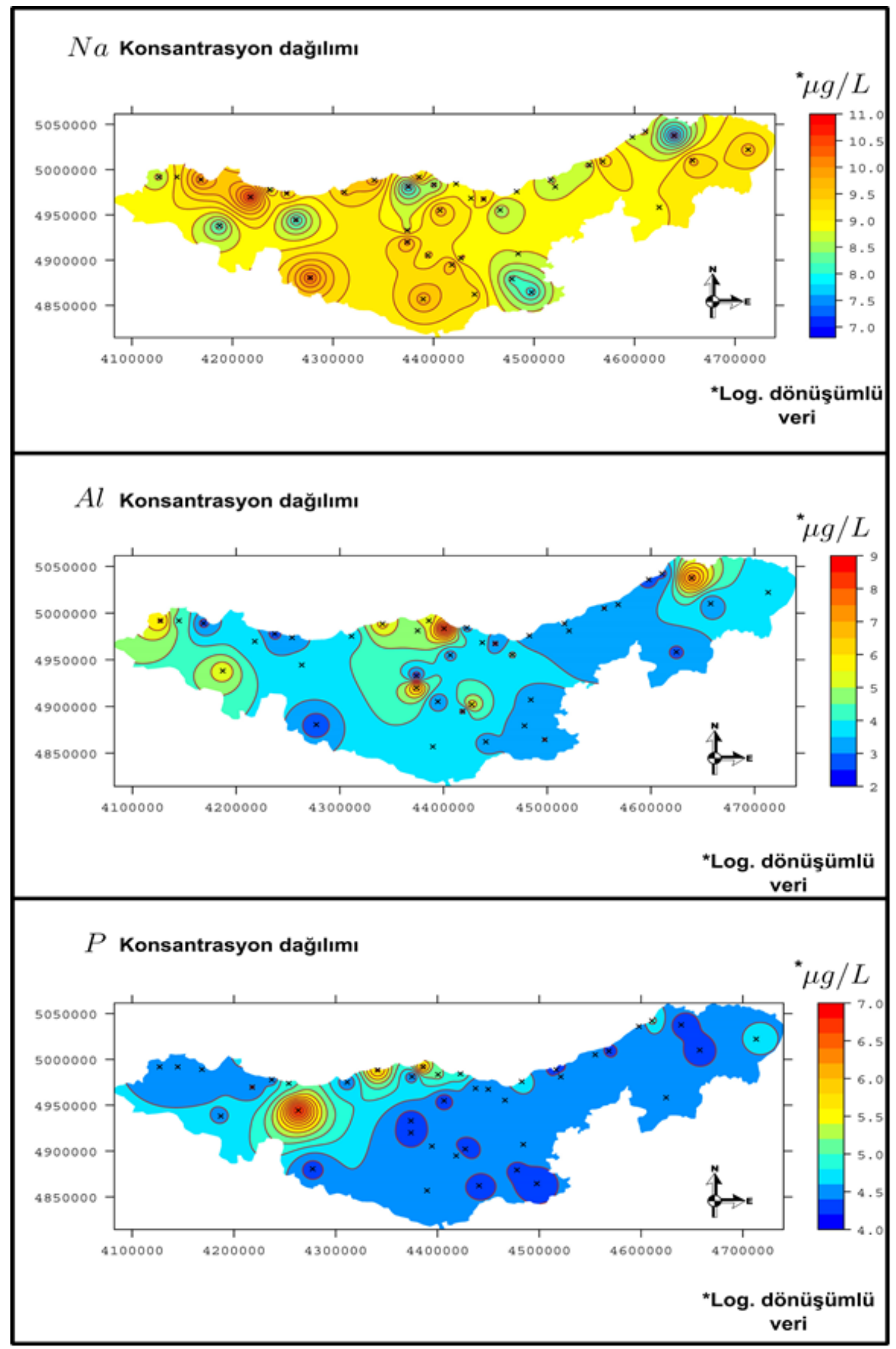

Şekil 3: Elementler için dağılım haritaları 


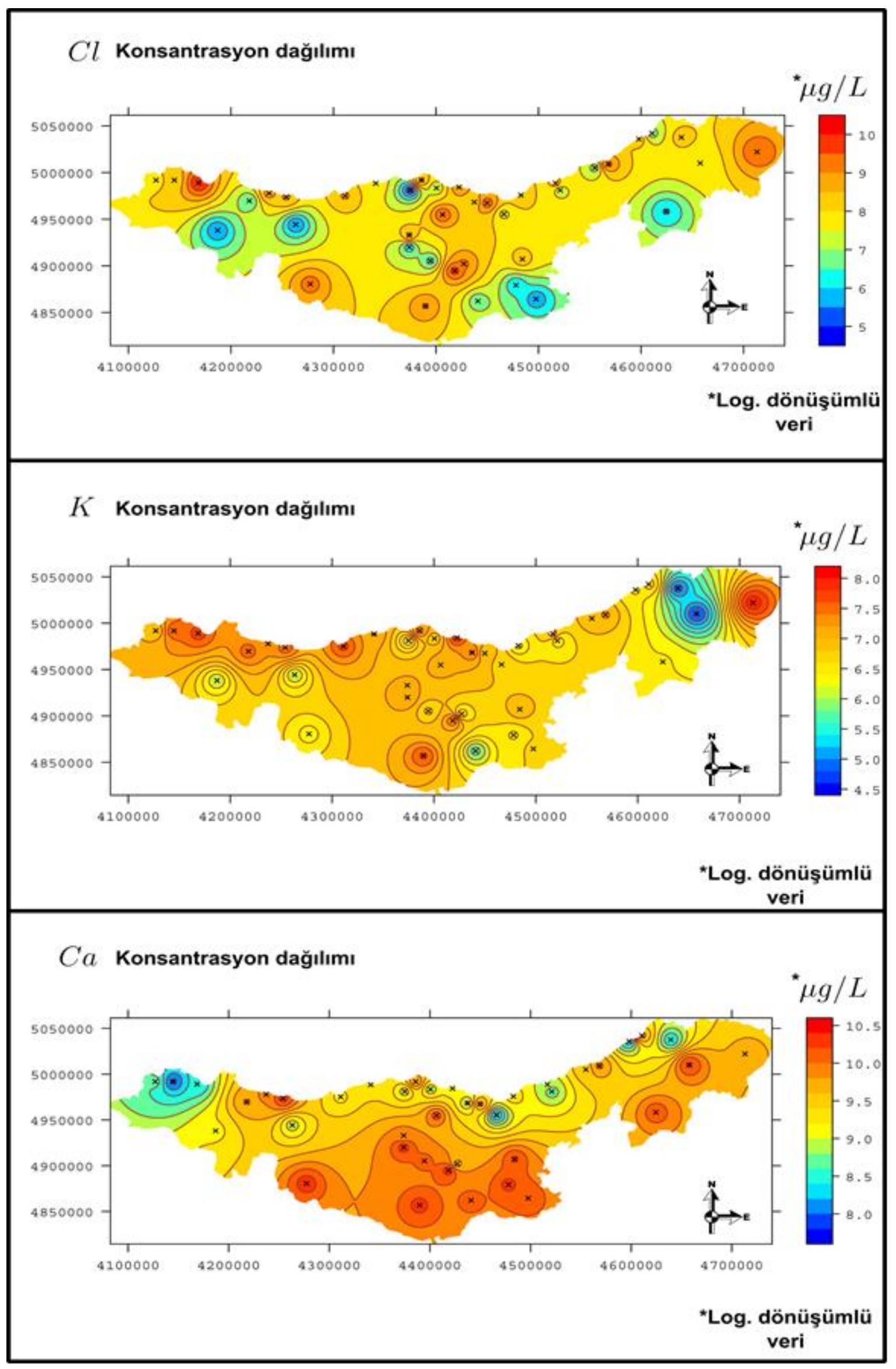

Şekil 3: Devamı 


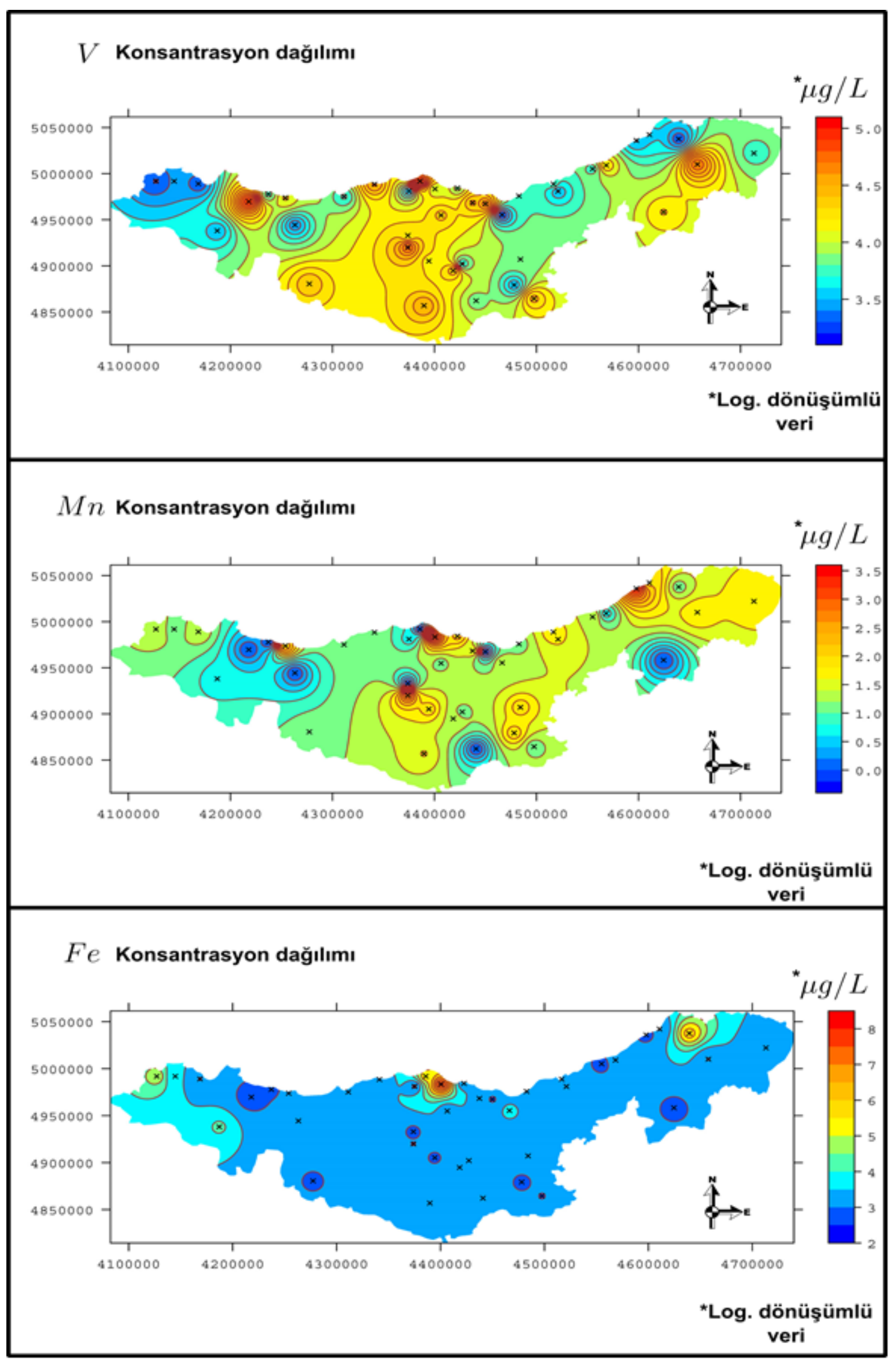

Şekil 3: Devamı 


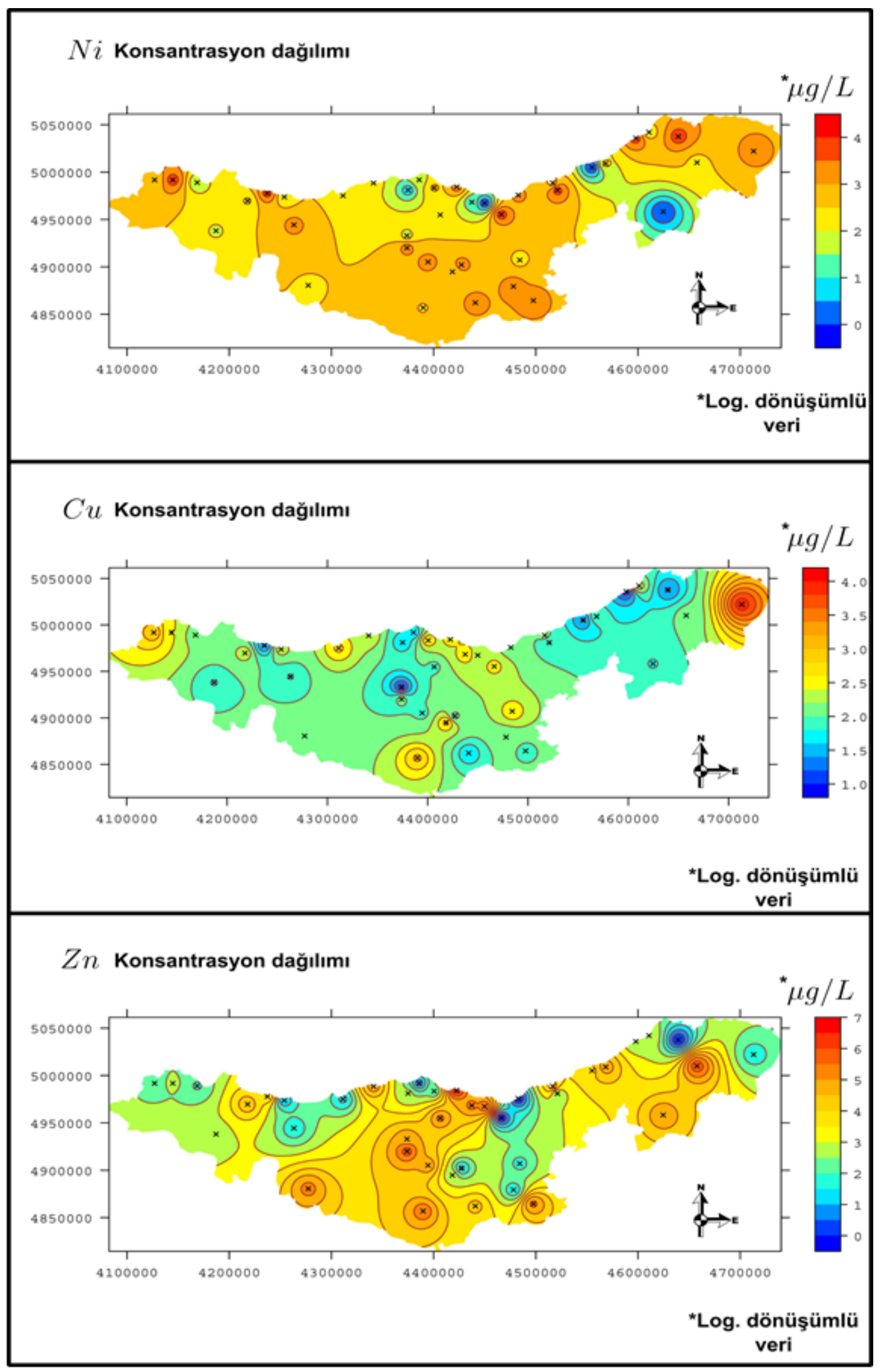

Şekil 3: Devamı 


\section{Kaynaklar}

Ahmad M.K., Islam S., Rahman S., Haque M.R., Islam M.M., (2010), Heavy metals in water, sediment and some fishes of buriganga river, Bangladesh, Int. J. Environ. Res, 4(2), 321-332.

Alabdula'aly A.I., Khan M.A., (2009), Heavy metals in cooler waters in Riyadh, Saudi Arabia. Environmental Monitoring and Assessment, 157(1-4), 23-28.

Armstrong M., (1998), Basic Linear Geostatistics, Springer-Verlag Berlin Heidelberg, Germany, 155ss.

Baume O., Skøien J.O., Heuvelink G.B.M., Pebesma E.J., Melles S.J., (2011), A geostatistical approach to data harmonization - Application to radioactivity exposure data, International Journal of Applied Earth Observation and Geoinformation, 13(3), 409-419.

Dabeka R.W., Conacher H.B., Lawrence J.F., Newsome W.H., McKenzie A., Wagner H.P., Pepper K., (2002), Survey of bottled drinking waters sold in Canada for chlorate, bromide, bromate, lead, cadmium and other trace elements, Food Additives and Contaminants, 19(8), 721-732.

Dragović S.D., Janković-Mandić L.J., Dragović R.M., Dordević M.M., Dokić M.M., (2012), Spatial distribution of the 226 Ra activity concentrations in well and spring waters in Serbia and their relation to geological formations, Journal of Geochemical Exploration, 112, 206-211.

Fatima I., Zaidi J.H., Arif M., Tahir S.N.A., (2007), Measurement of natural radioactivity in bottled drinking water in Pakistan and consequent dose estimates, Radiation Protection Dosimetry, 123(2), 234-240.

Ihaka R., Gentleman R., (1996), R: A Language for Data Analysis and Graphics, Journal of Computational and Graphical Statistics, 5(3), 299-314.

Isaaks E.H., Srivastava R.M., (1989), Applied Geostatistics (First Edition), Oxford University Press, London, U.K., 592ss.

Karamanis D., Stamoulis K., Ioannides K.G., (2007), Natural radionuclides and heavy metals in bottled water in Greece, Desalination, 213(1-3), 90-97.

Kobya Y., (2009), Doğu Karadeniz Bölgesindeki Doğal Kaynak ve Maden Sularında Radyoaktiflik Tayini, Doktora Tezi, Karadeniz Teknik Üniversitesi Fen Bilimleri Enstitüsü, Trabzon.

Krige D.G., (1966), Two-dimensional weighted moving average trend surfaces for ore-evaluation, J. South Afr. Inst. Min. Metall., 66, 13-38.

McGrath D., Zhang C., Carton O.T., (2004), Geostatistical analyses and hazard assessment on soil lead in Silvermines area, Ireland, Environmental Pollution, 127(2), 239-248.

Pebesma E.J., Bivand R.S., (2005), Classes and methods for spatial data in R, R News, 4(2), 9-13.

Pebesma E.J., Wesseling C.G., (1998), Gstat: a program for geostatistical modelling, prediction and simulation, Computers \& Geosciences, 24(1), 17-31.

Pérez-Rodríguez R., Marques M.J., Bienes R., (2007), Spatial variability of the soil erodibility parameters and their relation with the soil map at subgroup level, Science of the Total Environment, 378, 166-173.

Quantum GIS Development Team, (2014), Quantum GIS Geographic Information System, Open Source Geospatial Foundation Project, http://qgis.osgeo.org, [Erişim 23 Aralık 2016].

R Development Core Team, (2005), R: A language and environment for statistical computing, reference index version 2.2.1., http://www.r-project.org/, [Erişim 23 Aralık 2016].

Rosborg I., Nihlgård B., Gerhardsson L., Gernersson M.L., Ohlin R., Olsson T., (2005), Concentrations of inorganic elements in bottled waters on the Swedish market, Environmental Geochemistry and Health, 27(3), $217-227$.

Rusconi R., Forte M., Abbate G., Gallini R., Sgorbat G., (2004), Natural radioactivity in bottled mineral waters: A survey in Northern Italy, J. Radioanal. Nucl. Chem., 260(2), 421-427.

Sarma D.D., (2009), Geostatistics with Applications in Earth Sciences, Springer, Netherlands, 206ss.

T.C. Resmi Gazete, (2004a), Doğal Mineralli Sular Hakkında Yönetmelik (Să̆lık Bakanlı̆̆l), Sayl: 25657, Ankara, http://www.resmigazete.gov.tr/eskiler/2004/12/20041201.htm\#5, [Erişim 23 Aralık 2016].

T.C. Resmi Gazete, (2004b), Su Kirliliği Kontrolü Yönetmeliği, (Çevre ve Orman Bakanlı̆̆l), Sayl: 25687, Ankara, http://www.resmigazete.gov.tr/eskiler/2004/12/20041231.htm\#9, [Erişim 23 Aralık 2016].

Tavares M.T., Sousa a.J., Abreu M.M., (2008), Ordinary kriging and indicator kriging in the cartography of trace elements contamination in Sao Domingos mining site (Alentejo, Portugal), Journal of Geochemical Exploration, 98, 43-56.

Virha R., Biswas A.K., Kakaria V.K., Qureshi T.A., Borana K., Malik N., (2011), Seasonal variation in physicochemical parameters and heavy metals in water of Upper Lake of Bhopal, Bulletin of Environmental Contamination and Toxicology, 86(2), 168-174.

Webster R., Oliver M.A., (2007), Geostatistics for Environmental Scientists, Second Edition, John Wiley \& Sons Ltd., Chichester, UK., 330ss.

WHO, (2006), Guidelines for drinking-water quality (third edition), Geneva, Switzerland.

Xie Y., Chen T., Lei M., Yang J., Guo Q., Song B., Zhou X., (2011), Spatial distribution of soil heavy metal pollution estimated by different interpolation methods: accuracy and uncertainty analysis, Chemosphere, 82(3), 468-476. 